\title{
Time Perspective, Hope and Self-Regulation among Preparatory Year University Students: Exploring the Connections
}

\author{
Iman Osman Mukhtar Ahmed ${ }^{1}$ \\ ${ }^{1}$ Kulliyyah of Education, International Islamic University Malaysia, \\ Kuala Lumpur, Malaysia \\ imanosm@gmail.com
}

\begin{abstract}
This study aimed to investigate the relationship between time perspective, hope and selfregulation among foundation year students at a Malaysian public university. A survey questionnaire on the three constructs was completed by 118 Malay students aged between 18 to 21. The findings showed a significant positive correlation between the future time perspective and self-regulation ( $r=0.251, p=0.007)$. However, the association is a weak one. Likewise, a significant relationship was found between hope and two of the temporal orientations, i.e., the future orientation ( $r=0.399, p=0.001)$ and the past positive at $r=0.271, \mathrm{p}=0.003$., which is also considered a weak relationship. However, no significant association was observed between the past positive time perspective and students' self-regulation. On the contrary, the past negative and present-fatalistic time orientations have a significant negative relation with hope at $r=-0.308, p=0.001$ and $r=-0.207, p=0.028$, respectively. A similar result was obtained for the association between self-regulation and the PN orientation at $r=-0.290, p=0.002$. It was also found that hope and students' self-regulation are strongly correlated $(r=0.268, p=$ 0.004). In essence, the results imply that students with a high future time orientation are likely to have high levels of hope and self-regulation. Therefore, time perspective, especially the future orientation, and self-regulation skills could be important intervention factors for addressing students' academic obstacles. The findings of this study are beneficial for counselors, educators, and supervisors in designing intervention programs to help students become more positive and optimistic individuals.
\end{abstract}

Keywords: Time perspective, time orientations, hope, self-regulation, foundation students 


\section{INTRODUCTION}

The concept of time perspective (TP) was revived by Standford's professor of psychology, Phillip Zimbardo, to conceptualize the reality of a person's interest in and awareness of the passing of time. As a theory, TP postulates that as human beings, we subconsciously divide our personal experiences into three specific time perspectives, i.e., the past, the present, and the future, which are further broken down into five zones, i.e., the Past Negative (PN), Past Positive (PP), Present-Hedonistic (PH), Present-Fatalistic (PF), and Future TP. Zimbardo believes that time perspective, that is, how we look at time, influences many of our judgments, decisions, and actions. He argues that our time perspective substantially defines our character and personality and determines, to a certain extent, whether we are individuals stuck in the past, or people who live only for the moment, or persons enslaved by future ambitions (Sobol-Kwapińska, Jankowski, Przepiorka, Oinyshi, Sorokowski, \& Zimbardo, 2018).

To date, TP is the most prevalent concept and theory used to examine the relationship between time temporals and different personal experiences. TP illustrates how an individual's perception, behaviors, and feelings can be explained by their attitude based on time frames. According to Zimbardo and Boyd (1999), individuals who can reflect upon and benefit from multiple time perspectives are more likely to be psychologically and physically healthy and achieve high academic outcomes, in addition to being able to balance their temporal perspectives with different challenges (Campen, 2010; Tabar \& Zebardast, 2015). Hence, TP has been considered a strong psychological predictor of several behaviors in the health field (Ferrari, Stevens, Legler, \& Jason, 2012; Mann, de Ridder, \& Fujita, 2013; Olivera-Figueroa, Asthana, Odisho, Ortiz Velez, Cuebas \& Lopez Cordova., 2016).

TP develops during early childhood, where the child learns the meaning of time practically through live events. After acquiring an understanding of events and characterizing them in timebased frames, the child absorbs TP as an automatic process. In brief, TP is a fundamental process of acquiring and accumulating a total sum of individual experiences that shape a person's character, habits of mind and personality through his/her interaction with the family, community culture, religion, and education at an early age (Tabar \& Zebardast, 2015). Essentially, processes like socializing, modeling, education and mingling with people, as well as cultural and environmental factors, influence a person's time orientation, whether he/she is likely to center on or gravitate towards the past, present, or future when making decisions or taking actions (Seginer, 2003). Time perspective refers to the positive and negative behaviors of an individual towards the three time periods - the past, present, and future. In fact, even circumstantial factors such as going for a vacation, having an outing, or changing one's lifestyle can favor or be galvanized by a specific time perspective (Zimbardo \& Boyd, 1999). Presently, the main focus of TP research is the relationship between the present and future TPs and other psychological constructs (Tabar \& Zebardast, 2015).

Several recent studies have investigated the relationship between TP and psychological aspects that affect the individual's educational phase, especially during adolescence (Stănescu, $\&$ Iorga, 2015), because the success of such educational periods demands future-oriented 
strategies such as planning and setting future goals. Therefore, TP may prove useful in gauging the likely association between the decisions that youth and adolescents make, the expectations they have towards their studies, achievements, self-regulation, hope, and their future goals orientation (Ganzer, Caltabiano \& Hajhashemi, 2015; Baird et al., 2017). Through TP, young people develop future insights that include different tasks such as thinking about a future prospect, developing positive expectations for their future, clarifying their interest, constructing precise goals, and developing strategies to achieve the goals (Nurmi, 1991). Researchers believe that the ability to develop a time perspective that gradually focuses on the future-including having a proper vision of opportunities and the dreams to be achieved - is considered an essential developmental task of the period of young adolescence and young adulthood (Nurmi, 1991). It also plays a significant role in adolescents' motivation towards different aspects of life.

The second construct examined in this research was hope, which was also assessed based on time perspective. According to Nurmi (1991), hope is a cognitive process where individuals identify and exert efforts towards their desired goals. In other words, hope is a cognitive construct that reveals a person's motivation and ability to endeavor towards his/her goals. McElheran (2012) identified hope as "a thinking process, influenced by emotions, which takes place as an individual moves towards his or her goals" (p. 23). Therefore, hope is an important motivator that develops in a person an orientation towards the future, that is, looking to the future with a positive view and expectations (Ganzer et al., 2015). In fact, hope theory was established to help people live better lives through developing some future goals and the subsequent routes to achieve those goals (Snyder, Rand, \& Sigmon, 2002; McElheran, 2012). Based on theory and research, hope is characterized by two components, i.e., agency and pathways.

Agency is an individual's self-assurance and motivation to initiate and tolerate actions or efforts towards goal achievement, while pathways refer to their capability to conceptualize the routes to achieve the desired goal(s). Both agency and pathways are closely intertwined and positively related to each other (Snyder et al., 1991; McLoyd, Kaplan, \& Purtell, 2008). According to Snyder et al. (1991), individuals with high hopes have both the "will" and the "ways" to accomplish their goals.

Self-regulation is defined as one's ability to construct and implement an intended behavior in a flexible manner to achieve one's goals (Brown, Miller \& Lawendowski, 1999). It concerns one's ability to exercise control over one's emotions, thoughts, and behaviors, while striving to remain calm, and focused during stressful moments. This includes how one is able to regulate one's mental and emotional states, and health related habits to adjust with the challenging circumstances that one is forced to face (Strand, 2009; Stănescu, \& Iorga, 2015).

Several studies have endeavored to examine the precise relationship between TP and selfregulation and self-control, as both are considered to interact in a manner that affects behavior (Stănescu, \& Iorga, 2015; Barber, Munz, Bagsby, \& Grawitch, 2009). Furthermore, Avci (2013) suggested that applying self-regulation strategies can help students become successful in their academic activities. Therefore, for students to develop into competent self-regulated learners, 
they need to acquire cognitive learning skills and subsequently employ them to reach their academic goals. Moreover, they need to have meta-cognitive skills such as planning, monitoring, being mentally aware and alert, and adapting the learning process to suit their academic needs. They also need to have motivational attributes such as high self-efficacy and a clear goal orientation (Wolters, Pintrich, \& Karabenick, 2003). Researchers have suggested many self-regulation models that show how to deal with the elements that influence the learning process such as motivation, cognition, behavior, and the environment (Strand, 2009; Wolters et al., 2003).

\section{LITERATURE REVIEW}

\section{Time Perspective}

"Time perspective" (TP) was initially introduced as time perception by William James (18901950), an American psychologist, who argued that time is essentially a sensation (Zimbardo \& Boyd, 1999), although the idea was challenged by other scholars a century later (e.g., Myers, 1971). In the mid-20 ${ }^{\text {th }}$ century, the term was concretized by Frank (1939) and Lewin (1942) (Nurmi, 1991), and later rejuvenated by Zimbardo and his colleagues in 1985 (Zimbardo \& Boyd, 2008). Frank defined TP as cognitive prejudice towards a particular temporal state. It is also conceived as an individual adjustment variable connected to certain emotional and behavioral outcomes (Barber et al., 2009). Andretta, Worrell and Mello (2014) depicted 'time perspectives' as a multidimensional cognitive motivational construct that is distinguishable by two dimensions, i.e., the orientation and scope of the person. Kurt Lewin described TP as "the totality of the individual's views of his/her psychological future and psychological past that exist at any given moment" (McElheran, 2012, p. 7). However, the great attention presently given to the importance of TP is accredited to Philip Zimbardo and John Boyd, who established the first psychometric instrument known as the "Time Perspective Inventory" in 1999 to measure the time perspective of various groups (McElheran, 2012). They claimed that time perspective can be divided into five temporal zones, namely (1) the past-negative, (2) the pastpositive, (3) the present-hedonistic, (4) the present-fatalistic, and (5) the future, where the future was conceived to comprise a single construct. However, the findings of Beal (2011) pointed to future orientation as a multidimensional construct with multiple subconstructs, with each time temporal having its own behavioral, emotional, and social traits.

\section{Individuals with the Past-Negative (PN) Time Perspective}

These individuals have a negative view of the past that is characterized by pessimistic thinking and negative feelings. They tend to focus on all things that went wrong in the past. They view the past as a temporal zone that contains a lot of harm. Individuals with a PN orientation are seldom able to build good and healthy relationships with family members, especially with their parents and grandparents, as their minds tend to always conjure up past images and experiences related to what their parents and grandparents might have done wrong. Their social networks are characterized by a high degree of conflict. Individuals who are high on the PN time orientation are inclined to have a low self-esteem and poor impulse control and show aggressive 
behaviour. They also tend to be easily depressed and demonstrate a negative attitude towards most things (Zabelina, Chestyunina, Trushina, \& Vedeneyeva, 2018). Their negative behaviours include lying, stealing, uttering evil words to people and showing rude and socially noncompliant actions (Zimbardo \& Boyd, 1999; McElheran, 2012).

\section{Individuals with the Past-Positive (PP) Time Perspective}

These individuals generally have positive feelings and attitudes towards the past (Campen, 2010; Strand, 2009), with a tendency to look at it as a time of happy and lovely memories of people, events, and places, or in other words, the good old days (Zimbardo \& Boyd, 1999; Stolarski, Fieulaine, \& Zimbardo, 2018). Those who are high on the past-positive time orientation are usually outgoing people with high levels of self-esteem. They are less depressed, creative, responsible, and dependable. They have close bonds with their families and tend to have large social networks (Strand, 2009).

\section{Individuals with the Present-Hedonistic (PH) Time Perspective}

According to Zimbardo and Boyd (1999), these individuals are personified by pleasure-seeking and risk-taking attitudes. They have little apprehension about the future. Their focus is more on the present life and all the pleasure or benefit it can offer (Zabelina et al., 2018). Hedonism itself means the pursuit of pleasure and sensual self-indulgence, thus people with this type of time orientation tend to live for the here and now and seek to derive maximum pleasure from the present life (Stănescu, \& Iorga, 2015). High PH individuals have some similarities with people with the past-negative time orientation in that they exhibit poor impulse control, high tendencies towards depression and anxiety, aggression, and unstable emotions. At the same time, these individuals share some characteristics with the past-positive people like creativity and having large social networks (McElheran, 2012; Strand, 2009). Due to the way they think and view time, they are more likely to have high levels of physical energy and happiness and tend to exercise frequently. A downside of people with this time orientation is they can easily engage in negative behavior, such as gambling and sensation-seeking actions (e.g., street racing).

\section{Individuals with the Present-Fatalistic (PF) Time Perspective}

Present-Fatalistic (PF) TP individuals have a dark view of themselves and the future. They tend to exhibit behaviors that reflect poor self-esteem, low impulse control, and high degrees of depression, anxiety and aggression (McElheran, 2012). They also have a high likelihood of engaging in theft, lying, and sensation-seeking behaviors, even more than $\mathrm{PH}$ individuals (McElheran, 2012; Strand, 2009). As they are inclined to view the future with much negativity and pessimism, they tend to also believe that chance and luck play an essential role in what may take place in the coming future. As such, PF individuals tend to display an attitude that reflects hopelessness and helplessness (Tucholska, Gulla, Grabowska, \& Major, 2021). Because they believe they are governed by pure luck and chance, their overall demeanor will reflect the "whyeven-try-when-all-is-decided-by-luck" attitude (Zimbardo \& Boyd, 1999; Campen, 2010).

\section{Individuals with the Future Time (FT) Perspective}

People who are inclined to process events with a remote future time perspective are those who use intangible mental representations, specifically about far off future events. They frequently have creative, imaginative, positive and optimistic thoughts of the future (Zimbardo \& Boyd, 
2008). Individuals who are driven by the promise of the future are characterized by speculative thought, flexibility, adaptability, and high creativity, which includes creative problem-solving (McElheran, 2012; Strand, 2009). Additionally, they are quick decision makers and social extroverts who exhibit hopefulness and optimism in their view of the future, with an openness to new experiences and challenges (Stolarski, et al., 2018).

\section{Relationship Between TP and Hope}

Referring to the relationship between TP and hope, Snyder et al. (2002) described hope from the temporal perspective and through the goal orientation process. They asserted that individuals at the initial stage of the goal orientation process sustain hopeful thoughts through abstract depicting of some future state. These imagined images or pictures are identified as goals and they are followed by thought, emotion and behavior processes which are focused on achieving the stipulated goals. Driven by hope, individuals will strive to develop pathways or routes and work towards achieving the future goals. These routes can be considered as links that connect the present time to the anticipated future. Individuals with a future time (FT) perspective have high levels of hope and optimism (Kunwijaya, Sugiharto \& Sunawan, 2021), while those with a present fatalistic (PT) view tend to exhibit hopelessness (Zimbardo \& Boyd, 1999).

\section{Relationship between TP and Students' Self-Regulation}

Self-regulation has been described as "self-generated thoughts, feelings, and actions that are planned and cyclically adapted to the attainment of personal goals" (Zimmerman, 2000; cited in Stoffa, 2009, p. 14). According to Taylor (2012), self-regulation refers to learning strategies consciously selected and used by students to accomplish their goals. Researchers noted that high academic achievers with a high level of consciousness towards the future time perspective and motivation tend to exercise self-regulation through meta-cognitive learning strategies compared to low academic achievers. This is due to the former's inclination to spend more time preparing and planning their studies, which in turn has an impact on their academic achievement compared to the latter (Kattner, 2005). Kattner's (2005) study also found that students with low selfregulation skills spent less time on learning, which indicates the close relationship between students' future time perspective and self-regulation (Strand, 2009).

\section{Hope and Students' Self-Regulation}

Hope and self-regulation are among the factors that empower people and make them strive to achieve their future goals (Chang, 2009). Snyder (2002) explained that self-regulation includes any goal-oriented activity. At the same time, hopeful thinking is characterized by proper selfregulation, which comprises accurate feedback and changeable patterns in response to feedback. Vohs and Schmeichel (2002) referred to hope as good self-regulation, a psychological state that influences an individual's adequacy to accomplish his or her goal. There has been much research scrutinizing the relationship between time perspective and adolescents' behavior, goal 
orientations, academic achievement, life satisfaction, well-being, health, and risk-taking behavior (Strand, 2009; Tabar \& Zebardast, 2015; Stănescu, \& Iorga, 2015; Salmerón Pérez, Gutiérrez-Braojos, Rodríguez Fernández, 2017). However, limited research has explored the relationship between individuals' time perspective, hope, and self-regulation (Strand, 2009).

\section{Research Objectives}

Many researchers have investigated the relationship between TP and self-regulated learning, while giving less attention to how TP might be linked to hope and self-regulation. In the previous research conducted, almost none had used foundation or pre-university students as their sample and population. Furthermore, most of the studies that have explored and examined how people and/or cultural groups are acclimated to the past, present, and/or future were carried out in Western countries and the U.S. Only a small number of studies were conducted in Eastern cultures or contexts (Campen, 2010; Andretta et al., 2014). Therefore, the present study attempts to explore the temporal orientation of young Malaysian students and examine the relationship between time perspective, hope, and their self-regulation.

\section{METHODOLOGY}

\section{Research Design}

This research followed the quantitative cross-sectional survey design in collecting the data on students' time perspective, hope and self-regulation. The survey data were analyzed using Pearson correlation tests in version 24.1 of the Statistical Package for the Social Sciences (SPSS). Each of the scales measuring the three constructs (i.e., time perspective, hope and selfregulation) was scored according to its original scale assessment. A higher score on the scale indicates the domination of the measured characteristic or behavior.

\section{Population}

As an international university, the IIUM is one of the most highly ranked Malaysian higher education institutions, with learning centers that offer valuable and quality education to the Malaysian public and beyond. One of these important centers is the Center for Foundation Studies (CFS) and students who graduated from the IIUM CFS have better opportunities to enter Malaysian universities. Moreover, graduating from the foundation center gives students a head start towards becoming outstanding learners during their college studies. The IIUM CFS accepts approximately 8,000 students every year in different specializations that correspond to the degree programmes offered at the University. Data for the current research were collected during the short semester where the total number of enrolled foundation students was roughly 1,300 . 


\section{Sample}

A convenience sample of 118 CFS students (75 males and 40 females, with three students failing to indicate their gender) volunteered to partake in the current study. They were enrolled in different fields of specialization such as Economics and Architecture. Their ages ranged between 18 and $21(\mathrm{M}=18.4 ; \mathrm{SD}=1.23)$.

\section{Instruments}

This study utilized three separate questionnaires to investigate Malaysian foundation year students' TP and its relationship with self-regulation and hope-the short version of the Zimbardo Time Perspective Inventory (ZTPI), the adapted version of the Motivated Strategies for Learning Questionnaire (MSLQ) by Strand (2009), and the Adult Hope Scale by Snyder (1991). The Cronbach's alpha tests run on the study's data indicate varying levels of data reliability derived from the three questionnaires, i.e., $\alpha=0.618$ for Time Perspective, $\alpha=.521$ for Hope, and $\alpha=0.583$ for self-regulation. According to George and Mallery (2003), the rules of Cronbach's alphas values are as follows: $>.9=$ Excellent; $>.8=$ Good; $>.7=$ Acceptable; $>.6=$ Questionable; $>.5=$ Poor; and $<.5=$ Unacceptable. For the Hope and Self-Regulation scales, the Cronbach's alpha coefficients were poor $(\alpha<.6)$, while that for the TP scale was questionable $(\alpha<.7)$. Therefore, the reliability of the current study's data was below the acceptable threshold of 0.70 for social science constructs. The reliability results will be addressed in the study's limitations.

\section{The Zimbardo Time Perspective Questionnaire (ZTPI)}

The ZTPI assesses an individual's thoughts, preferences and attitudes that associate with his or her experiences throughout the three time frames - the past, present, and future-within five time zones (i.e., the PP, PN, PH, PF, and the Future). Its short version comprises 30 items that measure the five time zones which include "familiar childhood sights, sounds, smells often bring back a flood of wonderful memories", "if things don't get done on time, I don't worry about it" and "painful past experiences keep being replayed in my mind". The respondents replied to the statements on a 5-point Likert scale using the following anchors: Very Untrue (1), Somewhat Untrue (2), Neutral (3), Somewhat True (4), and Extremely True (5). The 30-item short version of the ZTPI has a verified high test-retest reliability, with coefficients ranging from 0.70 to 0.80 for the different factors. Before scoring the ZTPI, negative items (i.e., items 9,24 and 25) were reverse-coded. The score for each time zone was calculated by summing up the items representing the time zone and divided by the zone's total number of items.

\section{The Motivated Strategies for Learning Questionnaire (MSLQ)}

The MSLQ was developed by Beal (2011) to assess college students' motivational orientations and learning strategies. It consists of 81 items which are divided into two sections. These are the Motivational and Learning Strategies sections. The learning strategies section consists of 50 items that assess the respondents' cognitive and meta-cognitive skills, self-regulation, and 
resource management skills. For this study, the researcher selected 10 items from Strand's (2009) MSLQ to measure students' self-regulation in relation to time. These ten items were picked from the MSLQ, which included "I make good use of my study time for coursework" and "When I study for class, I set goals for myself in order to direct my activities in each study period". The estimated reliability of Stand's (2009) scale is $\alpha=0.83$. Respondents were asked to select one of these anchors-Strongly Disagree (1), Disagree (2), Neutral (3), Agree (4), and Strongly Agree (5) - to indicate their responses to the suggested self-regulation items. Four items (i.e., no 1, 3, 8 and 10) were negative items and were thus recoded. To calculate the selfregulation scores, the sum of the summated items was divided by the total number of items on the scale.

\section{The Adult Hope Scale (AHS)}

Developed by Snyder and colleagues in 1991, the AHS has 12 items presented in three parts. Four items (i.e., 2, 9, 10 and 12) measure agency (i.e., There are lots of ways around any problem). Another four items (i.e., 1, 4, 6 and 8) measure pathways (i.e., I energetically pursue my goals), while the remaining four items were filler items (not included in the scoring) (Snyder et al., 1991). The respondents were assessed on the three constructs using a 7-point Likert scale that ranged from Definitely False (1), Mostly False (2), Somewhat False (3), Neutral (4), Somewhat True (5), Mostly True (6), and Definitely True (7). The sum of agency and pathway scores was used to assess the Hope construct.

\section{Data Collection Procedure}

All permissions to collect data from the students were properly obtained, especially that from the IIUMCFS' Admission and Record Department. The respondents were also asked if they were interested to share their time perspectives in the survey before they were handed a copy of the questionnaire. The survey was administered manually in class with the help of the lecturers in charge and the researcher was present in the class to help the respondents if they needed any assistance and to collect the questionnaires right after they were filled out.

\section{Data Analysis}

The time perspective, hope and self-regulation data collected for the study were analyzed using descriptive statistics (i.e., frequency counts, percentages, means and standard deviations) and Pearson Product-Moment correlation. Before running the analysis, negative items were recoded and then scores for each scale were calculated. The latter analysis was run to examine the correlation among the study's three variables. 


\section{RESULTS}

\section{Respondents' Demographics}

Table 1 shows the demographic profile of the 118 CFS students who responded to the survey. Roughly, the sample was $34 \%$ male and $64 \%$ female. Three students did not indicate their gender $(2.5 \%)$. The students' ages ranged between 18 to 21 with a mean age of 18.4 (SD = 1.23). All respondents were Malay Malaysian.

\section{Table 1}

Respondents' Demographics $(N=118)$

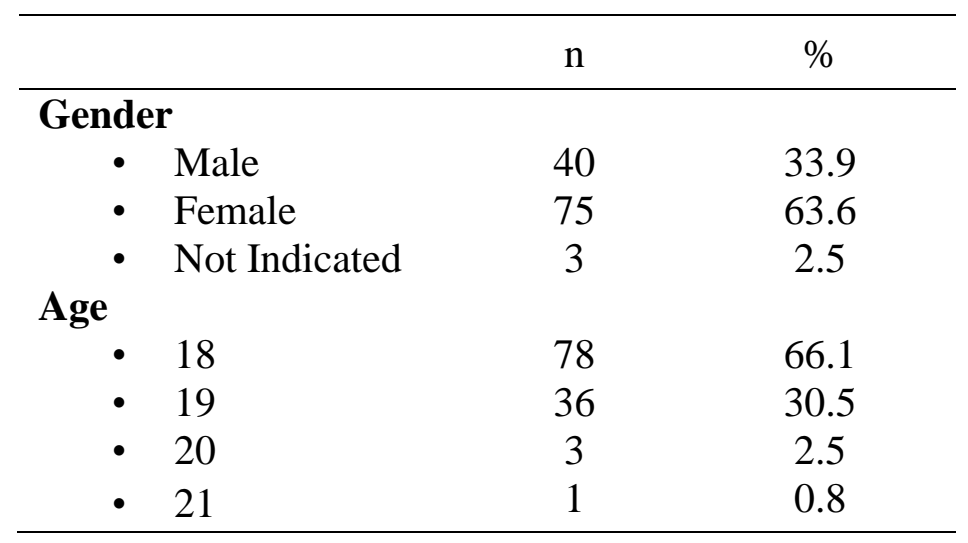

\section{Time Perspectives and Hope}

Table 2 displays the correlation between TP and hope. As indicated in the table, hope $(\mathrm{M}=$ $40.84, \mathrm{SD}=5.260$ ) correlated significantly with two of the temporal orientations, i.e., the future orientation at Pearson's $r(118)=.418, p=.000$; and the past positive, $r(118)=.234, p=.011$. On the other hand, hope correlated inversely (negatively) with both the present fatalistic $(\mathrm{M}=$ $3.02, \mathrm{SD}=0.818)$, Pearson's $r(118)=-.310, p=.001$; and the past negative $(\mathrm{M}=3.68 \mathrm{SD}=$ $0.623)$, Pearson's $r(118)=-.185, p=.045$. Although the coefficients were statistically significant at $p<.05$ (2-tailed), the relationships were, however, weak and insubstantial. Furthermore, no statistically significant relationship was indicated between hope and the present hedonistic time orientation $(\mathrm{M}=3.56, \mathrm{SD}=.409)$, Pearson's $r(118)=.156, p=.092$. Essentially, the present hedonistic time orientation demonstrated a weak association with hope.

Table 2

Correlations between Hope and the Five Time Perspectives $(N=118)$

\begin{tabular}{lccccc}
\hline & Future & $\begin{array}{c}\text { Present } \\
\text { Fatalistic }\end{array}$ & $\begin{array}{c}\text { Past } \\
\text { Negative }\end{array}$ & Past Positive & $\begin{array}{c}\text { Present } \\
\text { Hedonistic }\end{array}$ \\
\hline Pearson's $r$ & $.418^{* *}$ & $-.310^{* *}$ & $-.185^{*}$ & $.234^{*}$ & .156 \\
Sig. (2-tailed) & .000 & .001 & .045 & .011 & .092 \\
\hline
\end{tabular}

**. Correlation is significant at the 0.01 level (2-tailed)

*. Correlation is significant at the 0.05 level (2-tailed) 


\section{Time Perspectives and Self-Regulation}

The results revealed that the three time perspective zones correlated well with self-regulation. As presented in Table 3, the future time (FT) perspective correlated significantly and positively $(\mathrm{M}=3.587, \mathrm{SD}=0.374)$ with self-regulation $(\mathrm{M}=34.43, \mathrm{SD}=4.46)$, Pearson's $\mathrm{r}(118)=.355$, $\mathrm{p}=.000$. On the contrary, self-regulation demonstrated a significant inverse relationship with the negative past $(\mathrm{NP})(\mathrm{M}=3.68, \mathrm{SD}=0.624)$, Pearson's $\mathrm{r}(118)=-.239, \mathrm{p}=.009$. and present fatalistic $(\mathrm{PF})(\mathrm{M}=3.03, \mathrm{SD}=0.822)$, Pearson's $\mathrm{r}(118)=-.289, \mathrm{p}=.002$. This correlation was statistically significant at the $\mathrm{p}<.05$ alpha level (2-tailed). A significant correlation was not found between self-regulation and the other two temporal zones (i.e., the Present Hedonistic and Positive Past orientations).

Table 3

Correlations between Self-Regulation and the Five Time Perspectives $(N=118)$

\begin{tabular}{lccccc}
\hline & Future & $\begin{array}{c}\text { Present } \\
\text { Fatalistic }\end{array}$ & $\begin{array}{c}\text { Past } \\
\text { Negative }\end{array}$ & Past Positive & $\begin{array}{c}\text { Present } \\
\text { Hedonistic }\end{array}$ \\
\hline Pearson's $r$ & $.355^{* *}$ & $-.307^{*}$ & $-.239^{* *}$ & .171 & -.022 \\
Sig. (2-tailed) & .000 & .001 & .009 & .065 & .813 \\
\hline
\end{tabular}

**. Correlation is significant at the 0.01 level (2-tailed)

*. Correlation is significant at the 0.05 level (2-tailed)

\section{Hope and Self-Regulation}

Table 4 tabulates the results of the Pearson correlation tests between students' self-regulation and hope. Students' self-regulation $(\mathrm{M}=34.43, \mathrm{SD}=4.46)$ correlated significantly and positively with hope $(\mathrm{M}=40.84, \mathrm{SD}=5.260)$, Pearson's $\mathrm{r}(118)=.392, \mathrm{p}=.000$. Although significant and positive, the coefficient of .268 indicates a weak and insubstantial relationship. Additionally, the relationships between self-regulation and the two components of hope, i.e., pathways and agency, were examined. The findings showed that students' self-regulation correlated positively with both pathways $(\mathrm{M}=20.92, \mathrm{SD}=3.252), \mathrm{r}(118)=.286, \mathrm{p}=.002$; and agency $(\mathrm{M}=19.92, \mathrm{SD}=2.970), \mathrm{r}(118)=.382, \mathrm{p}=.000$. Both correlations were statistically significant at the $\mathrm{p}<.05$ alpha level (2-tailed).

\section{Table 4}

Correlations between Students' Self-Regulation and Hope $(N=118)$

\begin{tabular}{llccc}
\hline & Variable & Self-Regulation & Agency & Pathways \\
\hline \multirow{4}{*}{ Agency } & Pearson Correlation & $.382^{* *}$ & -- & $.434^{* *}$ \\
& Sig. (2-tailed) & .000 & & .000 \\
& & & & \\
\multirow{2}{*}{ Pathways } & Pearson Correlation & $.286^{* *}$ & $.434^{* *}$ & -- \\
& Sig. (2-tailed) & .002 & .000 & \\
\multirow{2}{*}{ Hope } & Pearson Correlation & $.392^{* *}$ & $.832^{* *}$ & $.861^{* *}$ \\
& Sig. (2-tailed) & .000 & .000 & .000 \\
\hline
\end{tabular}




\section{DISCUSSION AND RECOMMENDATIONS}

This paper explores the factors associated with the TP and temporal orientation of foundationyear students at a Malaysian public university. It also explores the likely relationships between time perspective, hope, and self-regulation. TP is examined by considering three temporal domains (i.e., the past, present, and future) divided into five time zones (i.e., PN, PP, PH, PF, and the Future). The results showed hope to be positively and significantly correlated with Past Positive and Future TP, but negatively associated with both the Past Negative and Present Fatalistic time orientations. However, all associations were weak and not practically important. The findings of the current study are consistent with the findings of Ganzer et al. (2015), where PP and future TP correlated significantly and positively with hope, while PF and PP correlated negatively with hope. However, the study found PH to have no correlation with hope, which contradicted Ganzer et al.'s (2015) findings that established a positive association between PH and hope. Similarly, many studies found Future TP to have a significant positive correlation with hope (Strand 2009; Campen, 2010; Kunwijaya et al., 2021). McElheran (2012) found that the future TP is weakly correlated with hope which conflicts with the findings of this study. The study's findings concur with the research literature on hope which indicates that Future TP is a highly important factor to the building of hope in students (Zimbardo \& Boyd, 2008).

Zimbardo and Boyd (1999; 2008) hypothesized that individuals with a future time orientation tend to be the most hopeful individuals, and those with the Present-Fatalistic orientation are the least hopeful. Future TP is associated with hope because individuals who have a future-oriented TP are hopeful and optimistic about their future. They can deal with challenges through adaptability and openness, and can successfully achieve their goals (Stolarski et al., 2018). Therefore, hope can be considered as an important aspect of students' behavior since it could help to overcome obstacles. On the contrary, students with the PN and $\mathrm{PF}$ time perspectives tend to have low levels of hope because they have a negative view about their future or their present lives with no planning for the future. According to Zimbardo and Boyd (1999), present-fatalistic individuals are often characterized as being hopeless and helpless.

On the association between TP and self-regulation, the current results are aligned with many studies that have been carried out on future TP and self-regulation. A strong positive correlation emerged between the future-oriented TP and self-regulation (Strand, 2009, Zebardast et al., 2011; Tabar \& Zebardast, 2015; Stănescu \& Iorga, 2015). Zimbardo and Boyd (1999) indicated that future-oriented individuals are more likely to attain higher academic achievements, while those with present-oriented and PN time perspectives tend to have lower academic achievements - perhaps because they believe that chance and luck play an essential role in the upcoming future. Such individuals tend to have the "why-even-try" hopeless attitude and are frequently characterized by negative feelings, anxiety, and inactivity. As a consequence, their self-regulation is low. Zebardast et al. (2015) described them as individuals with a low ability to control time, little self-regulation, and a tendency to avoid responsibility.

However, in the current study, no correlation was found between present fatalistic time perspectives and self-regulation, and this result can be attributed to the limited number of PF 
elements used in the short version of the ZTPI, which is one of the limitations of the current study.

With regard to hope, the construct is theorized to contain two components which are agency and pathways. Agency refers to an individual's motivation to initiate and tolerate actions or efforts towards goal achievement. Pathways refer to one's capability to conceptualize routes to achieve one's desired goals, which means individuals with high hope have both the "will" and the "ways" to accomplish their goals. Both agency and pathways are integrated and positively related to each other (Snyder et al., 1991; Kunwijaya et al., 2021). The present study found that students' self-regulation is linked to hope in a significant, positive association. Selfregulation is also significantly correlated with the two components of hope, i.e., pathways and agency, which means self-regulation can be considered as a factor for the two hope components. Self-regulation refers to the active learning strategies that students use to accomplish their goals (Taylor, 2012), which means students need to set learning or academic goals (Agency) and the routes (Pathways) to achieving them.

The findings in this paper are consistent with Chang (2009) and Mann et al. (2013) who pointed out that individuals who handle self-regulation issues effectively are often capable of handling their failures when they find themselves losing hope in achieving their goals or when their goals are threatened. It is possible to deduce from the current findings that self-regulation may predict students' ability to achieve their future goals as it helps them to set clear goals and decide the ways of achieving those goals.

\section{CONCLUSION}

The present study explored the relationship between time perspective, hope and self-regulation with a sample of 118 students IIUM CFS students. The results provide evidence of a positive association between future-oriented TP and the constructs of hope and self-regulation, while a significant negative correlation was found between the PN and PF temporal perspectives with both hope and self-regulation. However, there is no evidence of a substantial relationship between PH and hope or self-regulation. The study has several implications that can benefit the counseling services and programs at learning institutions. The instrument used in the study can be a useful tool to assess students' self-regulation skills pertaining to their academic engagement and their ability to set future goals and develop routes to achieve the goals. Understanding the reasons behind negative emotions such as negative feelings and thoughts about the past can help young students to control their behaviors and assess their reactions to people, events and stimuli. The study's findings have shown that time perspective, hope and self-regulation have a prevalent influence on people's behavior. Hence, counsellors can develop intervention programs to help enhance students' time perspective, self-regulation skills and hope as these will eventually help them be optimistic and strive for a better future.

Nevertheless, this study has several limitations. The findings obtained cannot be generalized to other contexts as the sample was limited to only one university's foundation 
center. Another limitation is the low reliability of the data measuring the three main constructs and the weak internal consistency of the items. According to Tavakol and Dennick (2011), the length of the questionnaire and the number of items of a scale can influence data reliability and the degree of internal consistency. In addition, the sample size and language barrier that may be present in the research instrument can also influence the value of Cronbach's alpha. During the data collection process, many respondents found it difficult to understand some of the questions and had inquired about their meanings from the researcher.

In view of these limitations, future research may consider employing the original versions of the Motivated Strategies for Learning Questionnaire (MSLQ) and the Zimbardo Time Perspective Inventory (ZTPI) rather than the shorter versions that the study used. the original versions with a larger pool of items may contribute to a higher reliability index of the constructs (Zebardast et. al., 2011; Avci, 2013). Future research that employs a mixed-method approach may also uncover new perspectives about the nature of students' time perspective, selfregulation skills and hope. Challenges in developing them among the students may also be revealed. Consequently, such in depth studies can help counsellors to plan a more effective intervention program for students to enhance their time perspective, self-regulation skills and hope towards a better future. 


\section{REFERENCES}

Andretta, J., Worrell, F. C., \& Mello, Z. R. (2014). Predicting Educational Outcomes and Psychological Well-Being In Adolescents Using Time Attitude Profiles. Psychology in the Schools, Vol. 51(5). Wiley Periodicals, Inc. DOI: 10.1002/pits.21762

Avci, S. (2013). Relations between self- regulation, future time perspective and the delay of gratification in university students. Education, Vol. 133(4), 525-537.

Baird, H. M., Webb, T. L., Martin, J., \& et al. (2017). The relationship between time perspective and self-regulatory processes, abilities and outcomes: a protocol for a meta-analytical review. BMJ. doi: 10.1136/bmjopen-2017-017000

Barber, L. K., Munz, D. C., Bagsby, P. G., \& Grawitch, M. J. (2009). When does time perspective matter? Self-control as a moderator between time perspective and academic achievement. Personality and Individual Differences 46, 250-253. Elsevier Ltd. doi:10.1016/j.paid.2008.10.007

Beal, S. J. (2011). The Development of Future Orientation: Underpinnings and Related Constructs. Doctor dissertation. University of Nebraska, Lincoln. Theses, Dissertations, and Student Research: Department of Psychology. Paper 32. http://digitalcommons. unl.edu/psychdiss/32

Campen, D. (2010). An investigation of achievement goals and time perspective in community college students engaged in a first-year experience course. (Doctor dissertation). University of South Carolina. ProQuest LLC.

Chang, C. A. (2009). Restoring hope and enhancing self-regulation. Advances In Consumer Research, 36843-845.

Ferrari, J. R., Stevens, E. B., Legler, R. \& Jason, L. A. (2012). Hope, Self-Esteem, And SelfRegulation: Positive Characteristics Among Men And Women In Recovery. J. Community Psychol., 40: 292-300. doi: 10.1002/jcop.20509

Ganzer, J., Caltabiano, N. J., \& Hajhashemi, K. (2015). Time Perspective, Hope, and Learning Strategy among Rural Australian University Students. British Journal of Education, Society \& Behavioural Science 10(4): 1-10. Article no.BJESBS.19449 ISSN: 2278-0998

George, D., \& Mallery, P. (2003). SPSS for Windows step by step: A simple guide and reference 11.0 update $\left(4^{\text {th }}\right.$ ed.). Boston: Allyn $\&$ Bacon

Kattner, T. (2005). What prospective students want most: Six new personas? Recruitment \& Retention in Higher Education, 19, 1-7.

Kunwijaya, I., Sugiharto, D. Y. P. \& Sunawan, S. (2021). Future Time Perspective and Its Influence on Life Satisfaction through Hope. Jurnal Bimbingan Konseling, 10 (2), 80-88. https://journal.unnes.ac.id/sju/index.php/jubk

Mann, T., de Ridder, D., \& Fujita, K. (2013). Self-regulation of health behavior: Social psychological approaches to goal setting and goal striving. Health Psychology, 32(5), 487. 
McElheran, J. N. (2012). Time Perspective, Well-being, and Hope. Master thesis. University of Alberta. Edmonton, Alberta. Ottawa: Library and Archives Canada.

McLoyd, V. C., Kaplan, R., \& Purtell, K. M. (2008). New Hope's Effects on Children's Future Orientation and Employment Experiences. An MDRC Working Paper. MDRC. Web site: www.mdrc.org.

Nurmi, J. E. (1991). How do adolescents see their future? A review of the development of future orientation and planning. Developmental Review, 11, 1-59.

Olivera-Figueroa, L. A., Asthana, S., Odisho, N., Ortiz Velez, A. L., Cuebas, K., \& Lopez Cordova, N. M. (2016). Emerging cross-cultural research: the role of time perspective on well-being, life satisfaction and mindfulness. In A. M. Columbus (Ed.), Advances in psychology research (Vol. 113). Hauppauge: Nova Science Publishers, Inc.

Salmerón Pérez, H., Gutiérrez-Braojos, C., Rodríguez Fernández, S. (2017). The relationship of gender, time orientation, and achieving self-regulated learning. Revista de Investigación Educativa, 35(2), 353-369. DOI: http://dx.doi.org/10.6018/rie.35.2.273141

Seginer, R. (2003). Adolescent Future Orientation: An Integrated Cultural and Ecological Perspective. Online Readings in Psychology and Culture, 6(1). http://dx.doi.org/10.9707/ 2307-0919.1056.

Snyder, C. R., Rand, K. L. \& Sigmon, D. R. (2002). Hope Theory: A Member of the Positive Psychology Family. Handbook of Positive Psychology. books.google.com. https://teachingpsychology.files.wordpress.com/2012/02/hope-theory.pdf.

Snyder, C. R., Harris, C., Anderson, J. R., Holleran, S. A., Irving, L. M., Sigmon, S. T. (1991). The will and the ways: Development and validation of an individual-differences measure of hope. Journal of Personality and Social Psychology, 60, 570-585.

Sobol-Kwapińska M, Jankowski T, Przepiorka A, Oinyshi I, Sorokowski P and Zimbardo P (2018) What Is the Structure of Time? A Study on Time Perspective in the United States, Poland, and Nigeria. Front. Psychol. 9:2078. doi: 10.3389/fpsyg.2018.02078

Stănescu, D. F., \& Iorga, M. E. (2015). An exploratory study regarding the relations between time perspective, achievement motivation and self-regulation. Management Dynamics in the Knowledge Economy Vol. 3 (1), pp.7-24; www.managementdynamics.ro. ISSN 2392-8042 (online) (C) College of Management (NUPSPA).

Stoffa, R. C. (2009) An examination of the factors underlying the motivation and learning strategies of generation 1.5 Korean American students. Doctor Dissertation. Duquesne University. USA: ProQuest LLC.

Stolarski, M., Fieulaine, N., \& Zimbardo, P. (2018). Putting time in a wider perspective: The past, the present, and the future of time perspective theory. The SAGE handbook of personality and individual differences. ff10.4135/9781526451163.n28ff. ffhal-02419830

Strand, K. H. (2009). Behavioral effects of consideration of future consequences and time perspective on self-regulation and procrastination in mastery and performance-oriented college students (Order No. 3448065). Available from ProQuest Dissertations \& Theses Global. (859251341). Retrieved from http://210.48.222.80/proxy.pac/docview/ 859251 341 ? accountid $=44024$. 
Tabar, M. S. \& Zebardast, A. (2015). Predicting academic achievement based on dimensions of time perspective among university students. Biological Forum - An International Journal 7(2): (Special Issue-I) 1-6.Tavakol, M. \& Dennick, R. (2011). Making sense of Cronbach's alpha. International Journal of Medical Education. 2,53-55. DOI: 10.5116/ijme.4dfb.8dfd. ISSN: 2042-6372

Taylor, R. T. (2012). Review of the Motivated Strategies for Learning Questionnaire (MSLQ) Using Reliability Generalization Techniques to Assess Scale Reliability. Doctor Dissertation. Auburn University. Auburn, Alabama. USA: ProQuest LLC.

Tucholska, K., Gulla, B., Grabowska, A., \& Major, P. (2021). Time perspective, future anxiety, and hope for success in individuals awaiting bariatric surgery. Health Psychology Report. https://doi.org/10.5114/ hpr.2021.105259

Vohs, K. D., \& Schmeichel, B. J. (2002). What Makes Hope Hopeful? The Relationship between Hope and Self-Regulation. Psychological Inquiry, 13(4), 318-321. http://www.jstor.org/stable/1448877

Wolters, C. A., Pintrich. P. R., Karabenick, S. A. (2003). Assessing Academic Self-regulated Learning. Paper prepared for the Conference on Indicators of Positive Development: Definitions, Measures, and Prospective Validity. Sponsored by ChildTrends, National Institutes of Health. March 2003

Zabelina, E., Chestyunina, Y., Trushina, I., \& Vedeneyeva, E. (2018). Time Perspective as a Predictor of Procrastination. SIM 2017 / 14th International Symposium in Management. Procedia - Social and Behavioral Sciences 238, 87 - 93.

Zebardast, A., Besharat, M. A., \& Hghighatgoo, M. (2011). The Relationship between SelfRegulation and Time Perspective in Students. Procedia - Social and Behavioral Sciences, 30(2nd World Conference on Psychology, Counselling and Guidance - 2011), 939-943. doi:10.1016/j.sbspro.2011.10.182.

Zimbardo, P. G., \& Boyd, J. N. (2008). The Time Paradox. New York: Free Press, Simon \& Schuster

Zimbardo, P. G., \& Boyd, J. N. (1999). Putting time in perspective: A valid, reliable individualdifference metric. Journal of Personality and Social Psychology, 77, 1271-1288 